\title{
Prioridades estratégicas em serviços de pós-venda de uma empresa de manufatura de base tecnológica
}

\author{
Strategic prioritization in after-sales services in a \\ manufacturing technology center
}

\author{
Miguel Afonso Sellitto ${ }^{1}$ \\ Miriam Borchardt ${ }^{1}$ \\ Giancarlo Medeiros Pereira ${ }^{1}$ \\ Mariélio Silva ${ }^{1}$
}

\begin{abstract}
Resumo: O objetivo deste artigo foi construir uma estrutura de temas estratégicos em serviços de pós-venda de uma empresa de manufatura de base tecnológica. O artigo faz uma revisão sobre operações e estratégia de pós-venda e apresenta a metodologia de pesquisa, o método de trabalho e os resultados de um caso-piloto em uma empresa de fabricação de equipamentos eletrônicos industriais. O método compreendeu sessões de grupos focados com especialistas que construíram uma estrutura de quatro temas estratégicos e vinte e três fatores de competição em pós-venda. A estrutura foi testada em questionário respondido por gestores da operação. Foram indagadas a importância e o desempenho da empresa nos fatores de competição da estrutura. Verificou-se que o fator reparos em bancada ou oficina tem mais desempenho que importância e está sobrevalorizado pela gestão. Também se verificou que os fatores testes acelerados, uso de confiabilidade em projeto e em garantia e uso de sistemas de informação para prospecção e para tratamento de clientes estão subvalorizados e poderiam receber mais recursos em uma eventual reformulação da estratégia de pós-venda. Os outros fatores mostraram-se equilibrados: os desempenhos avaliados são similares às importâncias atribuídas. Na continuidade, a pesquisa será estendida aos distribuidores da empresa que operam em campo a estratégia de pós-venda.
\end{abstract}

Palavras-chave: Serviços de pós-venda. Avaliação de desempenho. Estratégia de pós-venda.

\begin{abstract}
This paper aimed at constructing a structure for strategic themes in after-sales services of a manufacturing technology center. After-sales service operations and strategy are reviewed and the research methodology, and the findings of a case study in an industrial electronic equipment manufacturer were presented. The method included team work that together with experts developed a structure composed of four strategic themes and twenty-three after sale competitive factors. The structure was tested by a questionnaire administered to operations managers of the company. The company's importance and performance in terms of competition structure were investigated. It was found that the repair of parts on the bench or in the shop has more performance than importance, and it is overvalued by the company's management. It was also found that accelerated tests, design and warranty reliability, and employment of information systems in new business prospecting and customer relationship are undervalued and should receive more financial support with a reformulation of after-sales service strategy. Other factors seemed to be balanced: the results of evaluated performance were similar to those of the attributed importance. Further research will address the company's retailers that adopt after sale strategies.
\end{abstract}

Keywords: After-sales services. Performance assessment. After-sales strategy.

\section{Introdução}

As quedas observadas nos resultados de vendas de produtos primários têm estimulado empresas a olhar o serviço de pós-venda (After Sales Service - ASS) como alternativa de negócio. Serviços de pós-venda podem garantir receita mais estável que a venda de produtos primários, mais incerta, podem trazer retorno de informação de desempenho e contribuir para a fidelização de clientes (WAGNER; ZELLWEGER;
LINDEMANN, 2007). Tais serviços têm potencial de crescimento ainda pouco explorado (GEBAUER, 2008) e podem permitir a construção de vantagem competitiva por diferenciação e criação de valor para o cliente (GAIARDELLI; SACCANI; SONGINI, 2007).

Para Borchardt, Sellitto e Pereira (2008), uma empresa que produz bens manufaturados é considerada de base tecnológica se produzir bens de capital e

\footnotetext{
Programa de Pós-graduação em Engenharia de Produção e Sistemas, Universidade do Vale do Rio dos Sinos - Unisinos, Av. Unisinos, 950, CEP 93022-000, São Leopoldo, RS, Brasil, E-mails: sellitto@unisinos.br; miriamb@unisinos.br; gian@unisinos.br; marielio.silva@br.elster.com
}

Recebido em 27/10/2009 — Aceito em 8/2/2011

Suporte financeiro: CNPq. 
se o nível tecnológico presente for decisivo para o resultado do cliente final. São exemplos: equipamentos eletrônicos para uso industrial e em comunicações, máquinas operatrizes, veículos especiais fora de estrada e sistemas de condicionamento de ambiente. Os autores apontam que o serviço associado a este tipo de produto pode ser organizado sob a forma de uma operação complexa e apoiada em base tecnológica, chamando-a de operação de pós-venda. A importância de tais operações em manufatura de base tecnológica tem sido discutida por autores, tais como Lovelock e Wright (2002), Heskett, Sasser e Schesinger, (2002), Roth e Menor (2003) e Barry e Terry (2008), entre outros.

Operações de pós-venda associadas a produtos de base tecnológica têm gerado relações de longo prazo entre produtores e clientes (BORCHARDT; SELLITTO; PEREIRA, 2008), incluindo treinamento, manutenção, uso do produto, projeto e gestão de peças de reposição (MATHIEU, 2001). Barry e Terry (2008) separaram os serviços em pré-entrega (engenharia), junto com a entrega (instalação e treinamento) e pós-entrega (assistência técnica). Oliva e Kallenberg (2003) justificam serviços de pós-venda em manufatura de base tecnológica: i) expressivas receitas podem ser geradas por serviços especializados ao longo do ciclo de vida; ii) clientes têm demandado produtos de tecnologia mais complexa, que requerem serviços especializados; e iii) serviços são mais dependentes de talentos e mais difíceis de imitar, tornando-se fonte de vantagem competitiva. Borchardt, Sellitto e Pereira, (2008) acrescentam redução no custo de vendas, pois o serviço passa a ser um argumento de marketing junto ao cliente.

Algumas vezes, a relação com a competência essencial da empresa é imediata e imprescindível, tal como reparo de máquinas e fornecimento de peças de reposição. Outras vezes, torna-se um negócio específico, como observado em empresas de projetos e instalação. Com a entrega, nasce nova relação comercial de longo prazo, tal como ocorre com os ERP (Enterprise Resource Planning) e com sistemas integrados de gestão de manufatura, os CIM (BORCHARDT; SELLITTO; PEREIRA, 2008). Segundo Yanamandram e White (2006), conquistada a confiança, a tendência é que surja relação de longo prazo, pois dificuldades importantes surgem para o contratante em uma eventual troca de prestador de serviço.

Estudos estratégicos sobre pós-venda em produtos de base tecnológica não parecem surgir proporcionalmente na literatura (OLIVA; KALLENBERG, 2003; ROTH; MENOR, 2003; BRAX, 2005; SACCANI; JOHANSSON; PERONA, 2007). Borchardt, Sellitto e Pereira (2008), em pesquisa etnográfica, verificaram que a palavra-chave pós-venda pouco aparece na literatura de Engenharia de Produção. Como a operação de pós-venda tem sido fonte de vantagem competitiva, seu papel estratégico pode e deve ser estudado (SACCANI; JOHANSSON; PERONA, 2007). Em linhas gerais, uma estratégia de pós-venda deve incluir temas estratégicos, tais como serviços especializados de assistência técnica; acompanhamento e realimentação de informações de desempenho do produto; interface com clientes; e logística de peças de reposição.

Neste contexto, a questão de pesquisa deste artigo foi: como escolher e priorizar temas estratégicos na operação de pós-venda de uma empresa de manufatura de base tecnológica? O objetivo geral foi construir uma estrutura de temas estratégicos em uma operação de pós-venda de uma empresa de manufatura de base tecnológica. Os objetivos secundários foram: i) formar uma estrutura de temas estratégicos que comparecem em operações de pós-venda em manufatura de base tecnológica; ii) em um caso-piloto, priorizar a estrutura e avaliar o desempenho dos fatores que a compõem; e iii) no mesmo caso, discutir os fatores e apontar linhas de ação estratégicas para a gestão da operação. A principal contribuição de pesquisa foi a depuração dos temas constantes da estrutura proposta para a operação de pós-venda..

Algumas pesquisas similares, entre muitas outras, podem ser citadas. Wagner, Zellweger e Lindemann (2007) apontaram quatro aspectos principais na gestão de pós-venda de fabricantes de máquinas: i) logística de peças-reserva; ii) desempenho da base instalada; iii) marketing; e iv) uso estratégico dos serviços. Os autores também propuseram uma abordagem baseada no ciclo de vida do produto: i) novos produtos, instalação e posta em marcha; ii) treinamento para operação e manutenção; iii) desenvolvimento do processo, simulação e testes; iv) assistência técnica e peças-reserva; e v) reformas e modernizações. Bacchetti et al. (2008) organizaram a gestão das atividades de pós-venda em: i) sistema de informação; ii) logística de armazenagem e reposição; iii) recursos humanos; e iv) marketing. Saccani, Johansson e Perona (2007), em pesquisa empírica, identificaram: i) marketing; ii) serviços técnicos e peças de reposição; e iii) informações de desempenho. Hull e Cox (1994) descreveram como serviços de campo podem contribuir para ações de marketing na indústria de equipamentos eletrônicos. Suomala et al. (2004) analisaram a gestão de peças-reserva em fabricantes de máquinas. Lele (1997) apresentou um quadro de trabalho que pode ajudar fabricantes a identificar estratégias de pós-venda em função da evolução das necessidades de clientes e da tecnologia. Gaiardelli, Saccani e Songini (2007) e Cavalieri, Gaiardeli e Ierace, (2007) propuseram métodos para medição de desempenho e alinhamento estratégico em operações de pós-venda. Saccani, Johansson e Perona (2007) 
incluem o papel da cadeia de suprimentos na análise estratégica de pós-venda.

O restante do artigo está organizado em: i) revisão sobre serviços e estratégia de pós-venda; ii) apresentação da pesquisa; e iii) análise e discussão de resultados.

\section{Serviços e estratégia de pós-venda}

Baseados em referências, Saccani, Johansson e Perona (2007) definem operações de pós-venda em manufatura tecnológica como um conjunto de atividades após a compra, relacionadas ao uso, manutenção e disposição do produto. A satisfação de clientes não nasce apenas com o produto, mas também com o pacote de serviços oferecido e a estratégia de prestação do serviço (MALTHOUSE et al., 2004; STEWART, 2003; GEBAUER, 2008).

Serviços de pós-venda podem contribuir para fidelizar clientes e para a reputação da empresa junto a potenciais compradores (WAGNER; ZELLWEGER; LINDEMANN, 2007). Serviços de pós-venda são mais do que atendimento em garantia, pois esta é uma mera compensação quando o produto não atinge o desempenho esperado. Além de reparos técnicos, relacionam-se à evolução tecnológica e eventual substituição ou ampliação do equipamento (STEWART, 2003; HAYS; HILL, 2001; van DAAL, 2004). Ballou (2001) sugere a inclusão da rastreabilidade de produtos e a substituição temporária durante o reparo. Zackariasson e Wilson (2004) incluem a internet e os serviços remotos por meio eletrônico como alternativa para assistência técnica de equipamentos tecnológicos. Amini, Retszaff-Roberts e Bienstock (2005) incluem o papel da logística reversa na gestão de peças de pós-venda. O pacote de serviços, muitas vezes integrado por software de apoio, é chamado por Hirsch e Eschenbächer (2000) de produto estendido.

Diversos fatores justificam a necessidade de serviços de pós-venda (FIGUEIREDO, 2002): i) aumento da vida útil e do retorno financeiro de equipamentos por evolução tecnológica; ii) equipamentos mais complexos requerem mais serviços; e iii) a contratação em tempo integral de técnicos especializados pode não ser vantajosa, sendo preferível contratar na medida necessária. Borchardt, Sellitto e Pereira (2008) acrescentam: devido à diversidade de tecnologias, pode ser difícil reunir técnicos com todas as habilidades necessárias, sendo vantajoso contratar prestadores em tempo parcial.

Segundo Cohen, Agrawal e Agrawal (2006), em fabricação de equipamentos, as margens de lucro de serviços de manutenção e venda de peças de reposição podem ser até cinco vezes maior do que a venda primária. Viardort (2004) cita os casos da Snecma e da Bombardier, que produzem aeronaves e peças de reposição. Para estas empresas, o serviço de pós-venda representa $80 \%$ da receita, contra $20 \%$ do equipamento original. Reparos e venda de peças de reposição têm margens que podem chegar a 50\%; contratos de suporte e garantia podem superar os $75 \%$. Wagner, Zellweger e Lindemann (2007) mencionam que um terço do resultado da John Deere resultam de operações de pós-venda. Dennis e Kambil (2003) mencionam setores em que a média de volume de negócios devidos a operações de pós-venda pode chegar a $25 \%$ e os lucros a $50 \%$. Wise e Baumgartner (1999) apontam que operações de pós-venda podem faturar até três vezes o preço do produto ao longo do ciclo de vida. Mais recentemente, Bundschuh e Dezvane (2003) falaram em até cinco vezes.

Suomala et al. (2004) analisaram as implicações da diferenciação nos serviços de pós-venda, nomeadamente na gestão de peças-reserva. A diferenciação de bens de capital produz aumento na diversidade e na quantidade de itens de baixo volume, baixo giro de estoque e demanda errática, de difícil previsão. Segundo Suomala et al. (2002), na indústria de máquinas mecânicas, cerca de $10 \%$ dos itens são deste tipo. Os clientes mantêm cerca de 5\% em estoque, cabendo ao fabricante a manutenção dos demais, geralmente peças de alto valor e de alto prazo de garantia, que serão demandadas aleatoriamente. Os autores sugeriram usar peças padronizadas, mesmo em máquinas customizadas, para reduzir esta complexidade. Wagner, Zellweger e Lindemann (2007) apontam como alternativa a integração no fabricante das demandas dos poucos clientes, diminuindo a dispersão no tempo das requisições.

A prioridade das atividades de um serviço de pós-venda pode variar segundo a estratégia do produto. Por exemplo, serviços de manutenção e peças de reposição em equipamentos industriais geralmente têm mais prioridade do que informações comerciais, pois, para o comprador da máquina, é mais importante que esta produza continuamente. Já informações comerciais sobre produtos de consumo pessoal geralmente têm mais prioridade do que especificações de projeto. Para o comprador, via de regra, é mais importante saber preço e condições de pagamento do que taxa de compressão de motores. A estratégia do produto identifica a proposta do negócio e o valor que será oferecido aos clientes, em termos de serviços de pós-venda. Cabe à empresa produtora definir a abrangência e formular uma estratégia de prestação de serviços de pós-venda (BORCHARDT; SELLITTO; PEREIRA, 2008).

Os elementos essenciais que sustentam a formulação da estratégia de fabricantes de bens de base tecnológica e serviços associados são: i) criação de objetivos; ii) entendimento do ambiente; iii) conhecimento do mercado; iv) desenvolvimento de conceito de produto que integre bens e serviços; v) identificação dos resultados esperados para bens e serviços; vi) projeto das operações, produtividade desejada no uso dos 
recursos, definição da qualidade esperada na retaguarda e na linha de frente; e vii) competências requeridas em recursos humanos, instalações, cadeia de suprimentos e tecnologia da informação (JOHNSTON; CLARK, 2002; HESKETT; SASSER; SCHESINGER, 2002; ROTH; MENOR, 2003; CORREA; CAON, 2002). $\mathrm{O}$ detalhamento da estratégia para operações de pós-venda se insere em (vi) e (vii). Saccani, Johansson e Perona (2007) identificaram em pesquisa empírica três perfis estratégicos de empresas que se valem de operações de pós-venda: i) orientada por produto, que consideram inovação e qualidade como principal fator de competitividade; ii) orientada por serviço, que perseguem estratégias focadas em diferenciação de serviços; e iii) orientadas por volume, que buscam ganho de escala para competir por custo.

A formulação de estratégias de operações de pós-venda parece ser campo promissor para pesquisas, principalmente quando o serviço depende de redes de organizações autônomas que formam sistemas complexos com características de autoadaptação a emergências surgidas no ambiente de negócios. Em máquinas e equipamentos, o fabricante pode concentrar a fabricação na sede, com ganhos de escopo e de escala, e atuar com centros de serviços ou distribuidores, próximos aos clientes. Sistemas de informação, base de dados, mineração de dados, redes e tecnologias também podem ser úteis, principalmente na avaliação do desempenho de serviços e do produto em campo (BORCHARDT; SELLITTO; PEREIRA, 2008).

Alguns temas estratégicos em pós-venda foram identificados na literatura e foram úteis na pesquisa: i) logística de peças-reserva; ii) desempenho da base instalada; iii) marketing e relacionamento com clientes; iv) uso de serviços para atingir objetivos estratégicos; v) sistema de informação; e vi) recursos humanos. Estes temas surgiram na pesquisa empírica e foram descritos, reorganizados, estruturados e ponderados conforme a situação da empresa e opiniões de especialistas e gestores que participaram da pesquisa. $\mathrm{O}$ detalhamento dos temas surgiu na pesquisa empírica.

\section{A pesquisa}

Sellitto e Ribeiro (2004) propuseram uma estrutura para medição de objetos intangíveis complexos, baseada na teoria das medições, exposta em French (1986), e na filosofia da ciência, que pode ser usada para organizar os temas estratégicos que comparecem em gestão de serviços de pós-venda de base tecnológica. O ente de topo da estrutura é o termo teórico, explicado por construtos latentes, que se sustentam em conceitos, mais próximos da realidade, explicados por indicadores. Construtos e conceitos estruturam a grandeza intangível em níveis hierárquicos, construídos por teoria, conhecimento empírico ou opinião de especialistas. A organização assume a forma de sistema, desdobrado em subsistemas que recompõem e medem o sistema como um todo. Esta estrutura foi usada na pesquisa.

A questão de pesquisa foi: como escolher e priorizar temas estratégicos na operação de pós-venda de uma empresa de manufatura de base tecnológica? Para questões como, Yin (2001) aponta como método o estudo de caso. Wagner, Zellweger e Lindemann (2007) justificaram o estudo de caso como método de pesquisa pela ausência de base maior de conhecimento em gestão de pós-venda de fabricantes de máquinas. Voss et al. (2002) reconhecem o estudo de caso como alternativa de pesquisa em estudos de estratégia pelas peculiaridades que os casos apresentam.

Como é a primeira abordagem do objeto de pesquisa, optou-se por estudo exploratório. O caso exploratório levanta fatos e hipóteses para futuros estudos, que podem ser descritivos, se buscarem associações entre variáveis, ou explanatórios, se acrescentarem explicações (YIN, 2001). Segundo Eckstein (1975, apud ROESCH, 1999, p. 87), um estudo de caso pode contribuir de cinco modos para uma teoria. O primeiro modo oferece uma descrição profunda e específica de um objeto. $\mathrm{O}$ segundo modo interpreta eventuais regularidades como evidências de postulados teóricos mais gerais, ainda não verificados. O terceiro modo é heurístico: uma situação é deliberadamente construída para testar uma ideia. O quarto modo faz sondagens plausíveis acerca de uma teoria proposta pelo modo heurístico e o quinto modo, o caso crucial, apoia ou refuta a teoria. Nos três últimos modos, os objetivos são, em graduações, a exploração, a geração e o teste de teorias. Entende-se que a contribuição deste caso é do terceiro tipo: foi construída heuristicamente uma situação para o teste de uma ideia.

Tratou-se de um caso-piloto. Este caso, somado a outros, em profundidade e lateralidade crescentes, pode contribuir para uma futura teoria fundamentada (grounded theory) e eventualmente produzir um modelo generalista de análise estratégica de operações de pós-venda (EISENHARDT, 1999).

O método de trabalho foi: i) em sessões de grupo focado, três acadêmicos com experiência executiva em pós-venda e quatro praticantes propuseram uma estrutura composta por vinte e três conceitos, que organizou os temas estratégicos relevantes que podem estar presentes em operações de pós-venda de empresas de base tecnológica. O fio condutor da discussão foi composto por cinco perguntas relacionadas ao tema, em complexidade e abrangência crescentes, segundo o método apresentado em Ribeiro e Neumann (2003); ii) para teste da estrutura em caso-piloto, foi gerado um questionário com respostas categóricas, indagando sobre a importância e o desempenho de cada conceito e aplicados a três executivos gestores da operação de pós-venda de um fabricante de equipamentos eletrônicos industriais; 
e iii) as atribuições de importância e avaliações de desempenho dos temas foram usadas para uma análise estratégica da operação, segundo os vinte e três conceitos. Resultaram prioridades que poderão ser contempladas em eventual reformulação da estratégia de pós-venda da empresa.

\subsection{Estrutura estratégica de operações de pós-venda}

Foram conduzidas sessões de grupo focado com três pesquisadores acadêmicos, com experiência prévia executiva em pós-venda, e quatro especialistas praticantes da área. Um dos pesquisadores tem experiência acadêmica e executiva em fabricação e venda de máquinas. Os outros, em especificação, compra, instalação, manutenção e projeto. Os quatro praticantes têm formação em engenharia (dois são mestres em engenharia de produção) e possuem experiência em operações de pós-venda. $\mathrm{O}$ primeiro é mestre e possui mais de quinze anos de experiência executiva em operações de pós-venda ligadas à eletrônica industrial. O segundo também é mestre, tem atividade acadêmica e possui mais de dez anos de experiência em pós-venda de sistemas de condicionamento de ambientes. Ambos têm artigos publicados em congressos e revistas. O terceiro é mestrando e possui mais de vinte anos de experiência em operações de pós-venda de máquinas e veículos especiais, incluindo hidrogeradores, veículos fora de estrada, máquinas e veículos para mineração e construção rodoviária. O quarto possui pouco menos de dez anos de experiência em equipamentos para produção agroindustrial. Os participantes foram selecionados por sua capacidade de contribuição, pela expertise no tema e foram instados a se deterem em pós-venda referente a empresas de base tecnológica.

Um pesquisador mediou as sessões. As reuniões foram realizadas na universidade. Não houve cansaço ou impaciência, indicando que o tema foi adequado aos participantes. $\mathrm{O}$ moderador apresentou os objetivos, a forma de trabalho e de apresentação dos resultados. Os participantes foram cooperativos, gerando expectativa positiva e clima amistoso. Opiniões divergentes e diversidade nas percepções foram exploradas pelo moderador.

Como fio condutor da investigação, elaborou-se um roteiro de cinco questões.

A questão inicial teve como objetivo mobilizar os participantes: i) O grupo reconhece que as empresas operam em um cenário competitivo e que ganham ou perdem pedidos devido à presença ou ausência de certos atributos em seus negócios? A questão de transição encaminhou a discussão para o foco do problema: ii) Como o grupo descreve e interpreta o cenário competitivo em que a empresa opera? As questões centrais enfocaram definitivamente o problema: iii) $\mathrm{O}$ que o grupo entende por competitividade baseada em pós-venda? A questão de síntese foi: iv) Quais os temas ligados à operação de pós-venda que o grupo reconhece como capazes de gerar sucesso ou fracasso no cenário competitivo em que a empresa opera? A questão final encaminhou para o próximo passo da pesquisa: Como estes temas são constituídos? Os pesquisadores organizaram os depoimentos e comentários em quatro temas, divididos em fatores de competição. Em nova e última sessão, foi solicitado ao grupo que criticasse o achado, até que se chegou à estrutura definitiva.

Foram catalogados e organizados quatro temas presentes na operação de pós-venda que foram divididos em vinte e três fatores de competição. Os pesquisadores chamaram os temas de assistência técnica, confiabilidade, gestão do relacionamento com clientes e logística de retorno e reposição. Palavras-chave que podem descrever os temas são: capacidade técnica; informação de desempenho; relacionamento; e logística. A estrutura é apresentada no Quadro 1.

Em assistência técnica, os pesquisadores agruparam fatores de competição ligados à capacidade da empresa em fazer reparos, instalações, manutenção de campo e treinamento. No conceito (1), interessa considerar a capacidade que a empresa possui ou possa desenvolver de fazer o reparo de partes danificadas em bancada ou oficina, na fábrica. Em (2), o mesmo tipo de reparo é feito em campo. Há menos tempo até o atendimento e o cliente não precisa ter partes reserva. Em ambos os casos, o relato da falha ao projetista pode contribuir para melhoria do projeto. Em (3), interessa observar como a entrega técnica é feita, ou seja, que testes são feitos em fábrica (partes isoladas e sistema a vazio) e no campo (loop-test, teste de sistema a carga plena). Algumas vezes usa-se a expressão "posta em marcha" (start-up). Em (4), interessa observar como a empresa atende a clientes quanto ao modo de usar o produto ou fazer sua instalação. Clientes podem ser usuários finais do produto, distribuidores ou empresas de engenharia, que integram o produto com outros. Em (5), observa-se como está organizado o treinamento dos clientes. O treinamento pode ser comercial, para distribuidores, ou técnico, para integradores. Por fim, em (6), observa-se como está organizado o apoio documental ao cliente, ser em meio físico, catálogos, manuais de instalação, de peças de reposição e de resolução de problemas, e em meio virtual.

Em confiabilidade, foram agrupados fatores de competição ligados ao uso organizado de informações de campo para melhorar a qualidade do projeto e refinar o cálculo de garantia.

Em (7), interessa investigar como a empresa usa testes acelerados, baseados em uso intensivo do tempo ou em fatores de stress, tais como temperatura, vibração, umidade. Podem-se descobrir modos de falha que só apareceriam após anos de operação e calcular parâmetros de confiabilidade do projeto, tais como o tempo médio entre falhas (MTBF). Tais informações podem realimentar e corrigir o projeto 
Quadro 1. Organização dos fatores de competição em pós-venda.

\begin{tabular}{|c|c|c|}
\hline & Tema & Fatores de competição \\
\hline 1 & Assistência & Capacidade de fazer reparo de partes danificadas em bancada, na fábrica \\
\hline 2 & técnica & Capacidade de fazer reparo de sistemas, em campo \\
\hline 3 & & Procedimentos de entregas técnicas, com testes de equipamento e desempenho \\
\hline 4 & & Atendimento a consultas técnicas e orientação de clientes quanto ao uso do produto \\
\hline 5 & & Treinamento de clientes no uso e instalação do produto \\
\hline 6 & & Apoio documental ao cliente (manual de instalação e de troubleshooting) \\
\hline 7 & Confiabilidade & Uso de testes acelerados para detecção de problemas de projeto \\
\hline 8 & & Uso de testes na fábrica (burn-in) para detecção de problemas de fabricação \\
\hline 9 & & Aproveitamento de informações de desempenho de campo para melhoria de projeto \\
\hline 10 & & Conhecimento dos modos de falha do produto como arma de competição \\
\hline 11 & & Conhecimento da confiabilidade do produto como arma de competição \\
\hline 12 & & Uso da noção de confiabilidade para cálculo da garantia normalmente usada \\
\hline 13 & & Uso da noção de confiabilidade para cálculo de modelos avançados de garantia \\
\hline 14 & Gestão do & Sistema de informação para apoio ao relacionamento com clientes \\
\hline 15 & relacionamento & Sistema de informação para apoio à prospecção de mercado, vendas e negociação \\
\hline 16 & com clientes & Apoio documental ao relacionamento (jornais internos, informativos, mala direta) \\
\hline 17 & & Acompanhamento de desempenho de produtos e pesquisas de satisfação de clientes \\
\hline 18 & & Estrutura física e material, e ambientes adequados para atendimento a clientes \\
\hline 19 & Logística de & Coleta e retorno de embalagens e de resíduos de instalação e uso do produto \\
\hline 20 & retorno e & Coleta e retorno de equipamentos danificados, antes e após o conserto \\
\hline 21 & reposição & Armazenagem de peças de reposição para consertos em garantia \\
\hline 22 & & Armazenagem de peças de reposição para consertos sem garantia \\
\hline 23 & & Armazenagem de peças descontinuadas ou obsoletas para consertos sem garantia \\
\hline
\end{tabular}

antes da fabricação. Esta etapa coloca à prova o projeto. Em (8), é colocado à prova o processo de fabricação. Dado que o projeto está suficientemente depurado, após a fabricação e antes da entrega, um lote é submetido a um teste rápido e intenso sob fatores causadores de stress (burn-in). Este teste faz com que falhem em fábrica os indivíduos que falhariam no início da operação, reduzindo o período conhecido como mortalidade infantil. No item (9), observa-se como a empresa está estruturada para aproveitar as informações que vêm do campo e melhorar o projeto. Em (10), observa-se o que a empresa faz sobre os modos de falha relatados, tais como especificar redundâncias, prevenir na documentação técnica ou especificar peças-reserva que devem ser adquiridas junto com o produto. Em (11), observa-se o que a empresa faz com o cálculo da confiabilidade de produto e de sistema. Caso a confiabilidade do produto seja decisiva em relação à confiabilidade do sistema, devem-se prever configurações aumentantes, tais como paralelismo, redundância ou stand-by. Um exemplo é o uso de duas CPUs em configuração master-slave (um titular permanentemente monitorado por um reserva, pronto para assumir a função). Em (12), o cálculo de confiabilidade é usado para prever que retorno do produto deve ser esperado. Se a garantia for fixada por critérios de mercado (igual ou maior do que a concorrência), pela confiabilidade calculada é possível prever o custo de atendimento e encontrar um meio de custeá-lo. Em (13), o cálculo de garantia é usado para calcular tempos maiores do que os dos concorrentes. Se aumentar a confiabilidade, a empresa pode oferecer um período de garantia maior do que a concorrência.

Em gestão do relacionamento com clientes, foram agrupados fatores de competição ligados ao uso de informação comercial e ao modo de se relacionar com clientes.

Foram examinados os sistemas de informação que a empresa tem para se relacionar com clientes. Dentre estes sistemas, em (14), pode-se incluir o processamento e a armazenagem de informação relativa aos clientes, tais como nomes e cargos de contratantes, usuários de equipamentos, empresas de engenharia, parceiros em potencial e habilitações. Com este tipo de informação, podem-se montar estratégias de atendimento, contando com parceiros capacitados e bem localizados. Em (15), pode-se citar o controle de equipamentos já comprados e instalados por clientes e suas funcionalidades, o que pode ser a base para previsão qualitativa do volume e da localização de serviços. Para grandes volumes, o histórico de compras pode ser suficiente para previsão de demanda baseada em séries temporais. Caso se admita agregar a demanda por setor geográfico ou industrial, poucas 
informações originadas de muitos clientes podem ser suficientes para uma previsão agregada setorial confiável. Informações sobre demandas futuras podem ser importantes em uma estratégia de pós-venda, pois compras de matéria-prima e contratações de serviços podem ser antecipadas e criar vantagem aproveitando ganhos de escala e de escopo. Em (16), foi discutido o apoio documental ao relacionamento com os clientes, por exemplo, por malas diretas, newsletters ou workshops. Por exemplo, em workshops, a empresa pode apresentar novas funcionalidades em produtos, comunicando-as ao mercado e recebendo retorno sobre elas. Em oficinas com clientes (hands-on), a empresa pode tomar conhecimento das falhas ou deficiências que o produto tem apresentado, podendo servir como realimentação de projeto. Em (17), foi discutida a importância de pesquisas estruturadas de informação sobre o desempenho do produto em campo e satisfação de clientes. Em (18), foi discutida a importância de haver estrutura física capaz de comportar o relacionamento com os clientes, usuários e apoiadores do produto. Por exemplo, uma estrutura de trabalho que permita a empresas de engenharia ter acesso ao produto, fazer testes e discutir com projetistas. O distribuidor também pode criar uma estrutura para receber e apoiar clientes para testes, reparos, treinamentos ou reuniões.

Por fim, em logística de retorno e reposição, foram agrupados fatores ligados ao retorno de materiais e peças, armazenagem, recuperação e entrega rápida e confiável de materiais necessários ao uso do produto ao longo de sua vida útil.

Em (19), foi discutida a coleta e o retorno de embalagens e de resíduos de instalação e uso do produto. Pode ocorrer que embalagens de alto valor e materiais de instalação que possam ser reaproveitados, tais como cabos elétricos ou fibra ótica. Também pode ocorrer que as embalagens sejam retornáveis, por exemplo, feitas com plástico de engenharia. $\mathrm{O}$ reaproveitamento, além de criar uma imagem ambientalmente correta junto ao cliente, pode representar redução de custo. Em (20), vale o mesmo, porém para itens ativos. Em (21, 22 e 23), consideraram-se três aspectos da função armazenagem: peças para consertos obrigatórios, em garantia; para consertos contratáveis, fora de garantia; e para peças descontinuadas. No primeiro caso, a especificação e o cálculo do número de peças a armazenar leva em conta o prazo de garantia e a confiabilidade do produto. No segundo caso, considera-se a lucratividade do reparo, pois este passa a ser um negócio. No terceiro, são as garantias contratuais que definem que e quantas peças armazenar.

\subsection{Caso-piloto}

Os fatores de competição foram transformados em questionário com alternativas de respostas categóricas. Para refiná-lo e corrigir eventuais falhas nas perguntas, um teste foi feito com cinco respondentes, três membros do grupo focado que formulou a estrutura e dois gestores de pós-venda de um fabricante de base tecnológica. Adotou-se como pressuposto que fatores do mesmo tema são correlacionados, ou seja, ações que interferem em um também interferem em outros. Também foi assumido que ações em um tema pouco afetam outro tema. Por exemplo, uma ação de melhoria em armazenagem pode afetar todos os fatores do quarto tema, pois vários se valem de recursos comuns, tais como instalações físicas e sistemas de informação e apoio à decisão de armazenagem, mas não afeta os fatores dos outros temas.

Vários métodos já foram indicados na literatura para verificar a confiabilidade de escalas de indicadores: análise de variância (ANOVA), análise de correlação, coeficiente de Kappa, coeficiente intraclasse, divisão pela metade ou Alpha de Cronbach. A forma mais usada para estimar a confiabilidade de escalas é o Alfa de Cronbach. Tal estimativa informa o quanto os itens de uma mesma escala têm consistência interna: quanto mais consistentes, maior a confiabilidade do instrumento (HAYES, 2001). Hair et al. (1998) indicam que os valores do alfa devem ficar acima de 0,6 para estudos exploratórios e de 0,7 para confirmatórios. O teste foi feito, apesar do pequeno número de respondentes. O que se esperava obter não era uma estimativa absoluta de confiabilidade, mas o tema menos consistente e as perguntas que mais contribuíram para tal. Foi usado o software SPSS, v.17. Os resultados foram: Assistência técnica $=0,61$; Confiabilidade $=0,96 ; \mathrm{CRM}=0,67 ;$ e Logística $=$ 0,78. Decidiu-se reformular e explicar melhor os fatores (1) e (14). Com os fatores reformulados, testou-se a estrutura em um caso-piloto.

$\mathrm{O}$ caso-piloto foi conduzido com três gestores de pós-venda de um fabricante de instrumentos de medição de consumo de energia elétrica sediados na base centralizada da empresa. A empresa também opera com distribuidores. Os equipamentos podem ser usados em instalações industriais de alta e média tensão e em residências. Os três gestores coordenam as operações de pós-venda da empresa. Um é responsável pela gestão do relacionamento com os clientes, outro pela gestão do desempenho do produto, ligando os resultados de campo ao projeto e o terceiro pelas operações técnicas de campo e bancada.

A empresa executa a seguinte estratégia de operação: i) o projeto do produto é feito por técnicos e engenheiros locais empregados da empresa, em associação com universidades e centros de pesquisa afins e considera particularidades requeridas por clientes; ii) o fornecimento de materiais é feito por importadores em associações com redes locais de suprimento; iii) a venda é feita diretamente pela empresa e também por representantes autorizados; iv) a fabricação é feita para estoque para itens 
simples e sob encomenda para os especiais e confia em rede de fornecedores locais de subsistemas e serviços, organizados em cadeias de suprimentos; v) a montagem, teste e embalagem são feitas na empresa; vi) a distribuição e entrega são feitas pelos representantes; vii) os serviços associados e a entrega técnica são feitos por assistentes técnicos autorizados; e viii) boa parte da equipe é considerada como trabalhadores do conhecimento, com boa parcela oriunda de curso superior, inclusive pós-graduação. A estratégia é orientada por produto, pois tem características de inovação e valorização da qualidade como fonte de vantagem competitiva.

Os distribuidores representantes são centrais na estratégia de operação: são responsáveis por boa parte das ações de pós-venda. Têm autonomia para tratar com clientes sobre quase qualquer assunto, inclusive comerciais, requisições de serviços, peças, cotações e atividades de campo. São empresas qualificadas para serviços de assistência e possuem logística própria de transporte e armazenagem, atendendo rapidamente a demandas de serviços. Estão qualificadas para coletar informações de desempenho em campo e realimentar a empresa.

O questionário incluiu duas perguntas para cada fator: 1) Em sua opinião, qual a importância do [fator de competição] no mercado de competição em que a [nome da empresa] atua [muito alta $=5$; alta $=4$; média $=3$; baixa $=2$; muito baixa $=1]$ ?; e 2) Como você avalia o desempenho da [nome da empresa] quanto a [fator de competição] [ótimo $=5 ;$ bom $=$ $4 ;$ médio $=3 ;$ ruim $=2 ;$ péssimo $=1]$ ? A Tabela 1 apresenta as respostas. Nas colunas surgem os temas, os fatores, as respostas, as médias e a ordem crescente das médias e os coeficientes de variação $(c v=$ desvio padrão/média) e a ordem decrescente dos $c v$. Os fatores considerados mais importantes pelos respondentes foram $15,3,4$ e 20 . Os menos importantes foram $1,19,6,8,12,14$ e 22 . As menores variabilidades foram em 1, 3, 14, 20 e 22. As maiores foram em 11, 18 e 19. A Tabela 2 apresenta as correlações entre as respostas. Observa-se que todas são mais próximas a zero do que a 1 , o que pode indicar independência entre os respondentes.

O resultado da avaliação de desempenho da operação surge na Tabela 3 , semelhante à Tabela 1 . $\mathrm{O}$ respondente 2 teve dificuldades em responder diretamente a alguns itens e teve que pesquisar na empresa para completar suas respostas. Os maiores desempenhos foram em 1, 3 e 20. Os menores foram em 11, 12 e 13. As menores variabilidades foram em 5, 7 e 16. As maiores em 19, 8 e 6 . As correlações entre as respostas para desempenho surgem na Tabela 4. Neste caso, as correlações são significativamente maiores do que no caso anterior, o que pode indicar coerência interna nas avaliações.

Tabela 1. Importâncias atribuídas aos fatores.

\begin{tabular}{lrrrrrrrr}
\hline \multirow{2}{*}{ Tema } & Fator & \multicolumn{3}{c}{ Respondentes } & \multicolumn{5}{c}{ Estatísticas } \\
\cline { 2 - 9 } & & $\mathbf{1}$ & $\mathbf{2}$ & $\mathbf{3}$ & Média & Ordem & cv & Ordem \\
\hline Assistência técnica & 1 & 2 & 2 & 2 & 2,00 & 22 & 0,00 & 1 \\
& 2 & 3 & 3 & 4 & 3,33 & 10 & 0,17 & 10 \\
& 3 & 4 & 4 & 4 & 4,00 & 2 & 0,00 & 1 \\
& 4 & 4 & 3 & 5 & 4,00 & 2 & 0,25 & 14 \\
Confiabilidade & 5 & 4 & 4 & 3 & 3,67 & 5 & 0,16 & 7 \\
& 6 & 3 & 2 & 4 & 3,00 & 17 & 0,33 & 17 \\
& 7 & 4 & 3 & 4 & 3,67 & 5 & 0,16 & 7 \\
& 8 & 4 & 3 & 2 & 3,00 & 17 & 0,33 & 17 \\
& 9 & 5 & 3 & 3 & 3,67 & 5 & 0,31 & 15 \\
& 10 & 5 & 3 & 3 & 3,67 & 5 & 0,31 & 15 \\
& 11 & 5 & 3 & 2 & 3,33 & 10 & 0,46 & 21 \\
& 12 & 4 & 3 & 2 & 3,00 & 17 & 0,33 & 17 \\
& 13 & 4 & 3 & 3 & 3,33 & 10 & 0,17 & 10 \\
& 14 & 3 & 3 & 3 & 3,00 & 17 & 0,00 & 1 \\
& 15 & 5 & 4 & 4 & 4,33 & 1 & 0,13 & 6 \\
& 16 & 4 & 3 & 3 & 3,33 & 10 & 0,17 & 10 \\
& 17 & 4 & 4 & 3 & 3,67 & 5 & 0,16 & 7 \\
& 18 & 5 & 3 & 2 & 3,33 & 10 & 0,46 & 21 \\
& 19 & 1 & 4 & 1 & 2,00 & 22 & 0,87 & 23 \\
& 20 & 4 & 4 & 4 & 4,00 & 2 & 0,00 & 1 \\
& 21 & 4 & 3 & 3 & 3,33 & 10 & 0,17 & 10 \\
& 22 & 3 & 3 & 3 & 3,00 & 17 & 0,00 & 1 \\
& 23 & 2 & 4 & 4 & 3,33 & 10 & 0,35 & 20 \\
\hline \multirow{3}{*}{ Logística pós-venda } & 19 & & & & & & &
\end{tabular}


Considerando cada respondente como variável (não como caso), o alfa calculado foi 0,71 . Os resultados de importâncias e desempenhos são apresentados graficamente na Figura 1.

\subsection{Discussão}

Os resultados podem ser usados para análise e eventual reformulação da estratégia de pós-venda com base na visão dos gestores sediados na sede central da empresa.

Um método é por análise gráfica bidimensional dos resultados, recorrente na literatura. Até quanto se pesquisou, a referência mais antiga foi Slack (1993). Também surge em Paiva, Carvalho e Fenstenseifer, (2004) e Carvalho e Laurindo (2007). O fundamento do método é que um fator deve ter desempenho avaliado próximo à importância atribuída. Como as escalas são as mesmas [1 - 5], a comparação é direta. Caso um fator tenha mais importância do que desempenho, a estratégia da empresa o está valorizando menos do que devia e uma boa medida

Tabela 2. Correlações entre respostas para a importância.

\begin{tabular}{ccc}
\hline & Respondente 1 & Respondente 2 \\
\hline Respondente 2 & 0,022 & \\
Respondente 3 & 0,160 & 0,125 \\
\hline
\end{tabular}

seria alocar mais recursos produtivos, financeiros e de pessoal neste tema. Como recursos são finitos e geralmente restringidos, uma alternativa é realocar recursos que estejam sendo empregados nos fatores em que o desempenho é superior à importância. Caso todos os fatores tenham mais desempenho do que importância, é possível que a operação esteja

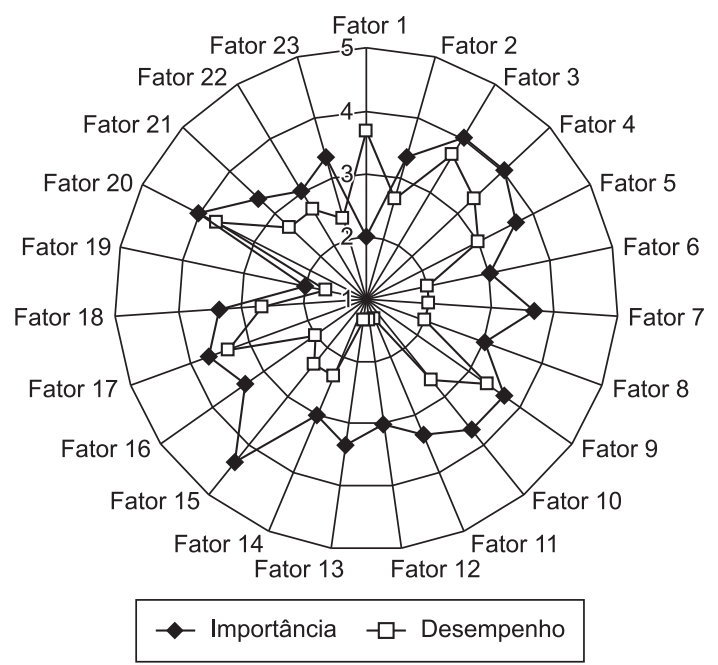

Figura 1. Representação gráfica das importâncias e desempenhos médios dos fatores.

Tabela 3. Avaliação de desempenho dos fatores.

\begin{tabular}{lrrrrrrrr}
\hline \multirow{2}{*}{ Tema } & Fator & \multicolumn{3}{c}{ Respondentes } & \multicolumn{5}{c}{ Estatísticas } \\
\cline { 2 - 8 } & & $\mathbf{1}$ & $\mathbf{2}$ & $\mathbf{3}$ & Média & Ordem & cv & Ordem \\
\hline Assistência técnica & 1 & 3 & 3 & 5 & 3,67 & 1 & 0,31 & 15 \\
& 2 & 2 & 2 & 4 & 2,67 & 8 & 0,43 & 16 \\
& 3 & 3 & 4 & 4 & 3,67 & 1 & 0,16 & 4 \\
& 4 & 3 & 3 & 4 & 3,33 & 4 & 0,17 & 6 \\
Confiabilidade & 5 & 3 & 3 & 3 & 3,00 & 7 & 0,00 & 1 \\
& 6 & 3 & 1 & 2 & 2,00 & 16 & 0,50 & 21 \\
& 7 & 2 & 2 & 2 & 2,00 & 16 & 0,00 & 1 \\
& 8 & 2 & 1 & 3 & 2,00 & 16 & 0,50 & 21 \\
& 9 & 3 & 3 & 4 & 3,33 & 4 & 0,17 & 6 \\
& 10 & 2 & 2 & 4 & 2,67 & 8 & 0,43 & 16 \\
& 11 & 2 & 1 & 1 & 1,33 & 21 & 0,43 & 16 \\
& 12 & 2 & 1 & 1 & 1,33 & 21 & 0,43 & 16 \\
& 13 & 2 & 1 & 1 & 1,33 & 21 & 0,43 & 16 \\
& 14 & 2 & 2 & 3 & 2,33 & 13 & 0,25 & 12 \\
& 15 & 2 & 2 & 3 & 2,33 & 13 & 0,25 & 12 \\
& 16 & 2 & 2 & 2 & 2,00 & 16 & 0,00 & 1 \\
& 17 & 3 & 3 & 4 & 3,33 & 4 & 0,17 & 6 \\
& 18 & 3 & 3 & 2 & 2,67 & 8 & 0,22 & 9 \\
& 19 & 1 & 3 & 1 & 1,67 & 20 & 0,69 & 23 \\
& 19 & 3 & 4 & 4 & 3,67 & 1 & 0,16 & 4 \\
& 20 & 3 & 3 & 2 & 2,67 & 8 & 0,22 & 9 \\
& 21 & 3 & 3 & 2 & 2,67 & 8 & 0,22 & 9 \\
& 22 & 2 & 2 & 3 & 2,33 & 13 & 0,25 & 12 \\
\hline
\end{tabular}


consumindo recursos excessivos e estes possam ser realocados a outras operações. Caso todos tenham mais importância do que desempenho, é possível que à operação tenham sido alocados recursos insuficientes, que deverão ser requisitados de outras operações.

A Tabela 5 apresenta as importâncias e desempenhos médios por fatores e as lacunas estratégicas, ou seja, a diferença entre importância e desempenho. Os fatores que apresentam maior lacuna são 15, 13 e 11. As menores são 1, 9, 3, 19, 20 e 22. O fator (1), capacidade de fazer reparo de partes danificadas em bancada, na fábrica, foi o único considerado excessivo. Os respondentes entendem que o atual desempenho no fator é superior à sua importância, ou seja, a empresa aloca recursos excessivos nesta atividade. Todos os demais fatores foram considerados em falta: tem menos desempenho do que importância.

As Figuras 2 e 3 apresentam as importâncias atribuídas e os desempenhos avaliados dos fatores. $\mathrm{Na}$ Figura 2, foi usado o método original proposto em Slack (1993). As proporcionalidades originais foram mantidas. O autor definiu quatro zonas: excesso,

Tabela 4. Correlações entre respostas para o desempenho.

\begin{tabular}{lcc}
\hline & Respondente 1 & Respondente 2 \\
\hline Respondente 2 & 0,5378 & - \\
Respondente 3 & 0,4591 & 0,5144 \\
\hline
\end{tabular}

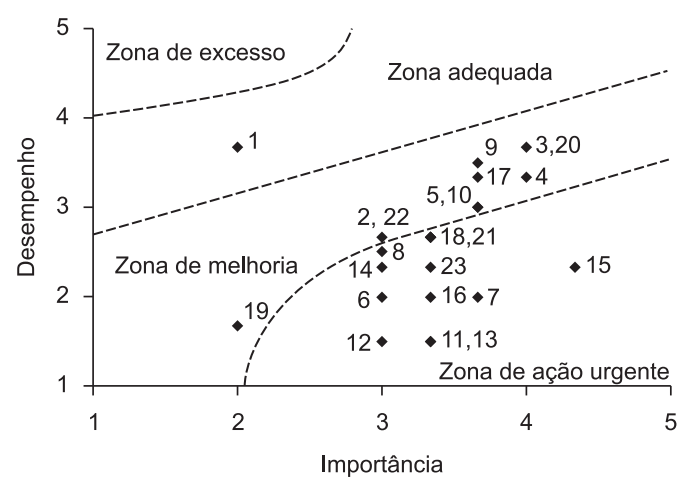

Figura 2. Análise bidimensional original de fatores estratégicos em pós-venda.

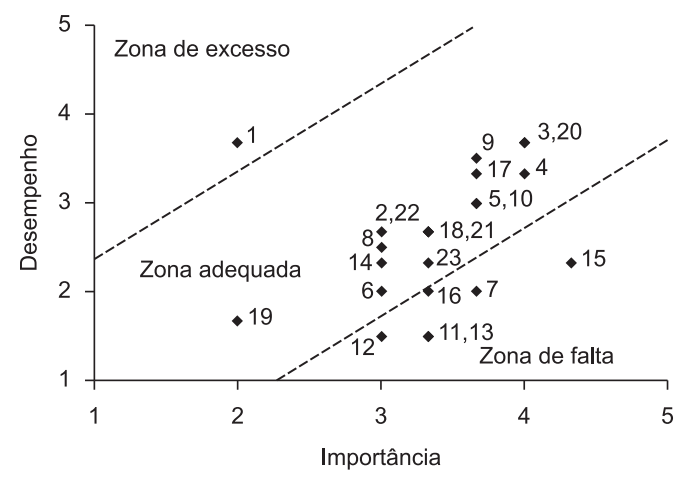

Figura 3. Análise bidimensional variante de fatores estratégicos em pós-venda.

Tabela 5. Análise bidimensional de fatores estratégicos.

\begin{tabular}{lcccccc}
\hline \multirow{2}{*}{ Tema } & Fator & \multicolumn{5}{c}{ Análise dos fatores } \\
\cline { 3 - 6 } & & Import. & Desemp. & Lacuna & Situação & Ordem \\
\hline Assistência técnica & 1 & 2 & 3,67 & $-1,67$ & excesso & 23 \\
& 2 & 3,33 & 2,67 & 0,66 & falta & 13 \\
& 3 & 4 & 3,67 & 0,33 & falta & 18 \\
Confiabilidade & 4 & 4 & 3,33 & 0,67 & falta & 9 \\
& 5 & 3,67 & 3 & 0,67 & falta & 11 \\
& 6 & 3 & 2 & 1 & falta & 8 \\
& 7 & 3,67 & 2 & 1,67 & falta & 4 \\
& 8 & 3 & 2,5 & 0,50 & falta & 16 \\
& 9 & 3,67 & 3,5 & 0,17 & falta & 22 \\
& 10 & 3,67 & 3 & 0,67 & falta & 11 \\
& 11 & 3,33 & 1,5 & 1,83 & falta & 2 \\
& 12 & 3 & 1,5 & 1,50 & falta & 5 \\
& 13 & 3,33 & 1,5 & 1,83 & falta & 2 \\
& 14 & 3 & 2,33 & 0,67 & falta & 9 \\
& 15 & 4,33 & 2,33 & 2,00 & falta & 1 \\
& 16 & 3,33 & 2 & 1,33 & falta & 6 \\
& 17 & 3,67 & 3,33 & 0,34 & falta & 17 \\
& 18 & 3,33 & 2,67 & 0,66 & falta & 13 \\
& 19 & 2 & 1,67 & 0,33 & falta & 18 \\
& 20 & 4 & 3,67 & 0,33 & falta & 18 \\
& 21 & 3,33 & 2,67 & 0,66 & falta & 13 \\
& 22 & 3 & 2,67 & 0,33 & falta & 18 \\
& 23 & 3,33 & 2,33 & 1 & falta & 7 \\
\hline
\end{tabular}


adequada, melhoria e ação urgente. Na Figura 3, foi usada a variante apresentada teoricamente em Sellitto (2005) e aplicada em Sellitto e Walter (2006) e Luz, Sellitto e Gomes (2006). O autor definiu como critério de separação que cada zona devesse ocupar um terço da faixa disponível a partir da origem. Resultam três regiões: falta, adequada, excesso. Obtiveram-se duas classificações diferentes para os fatores.

Na primeira análise, apenas o fator (1), capacidade de fazer reparo de partes danificadas em bancada, na fábrica, é considerada adequada. Os demais fatores são apontados como alvo de potenciais melhorias. Em particular, os fatores (6), (7), (8), (11), (12), (13), (14), (15), (16), (18), (21) e (23) requerem ações urgentes, pois seus desempenhos são sensivelmente menores do que suas importâncias. Na segunda análise, (1) é considerado em excesso e (7), (11), (12), (13), (15) e (16) requerem ações. Os demais são considerados adequados e devem apenas ser monitorados para que assim permaneçam.

Para o caso, foi adotada como base de análise a variante da Figura 3. A figura foi mostrada aos três gestores respondentes, os quais fizeram considerações acerca de possíveis alternativas de ação. Caso a análise motive um processo de planejamento estratégico em pós-vendas, a empresa pode aportar novos recursos aos fatores prioritários ou redirecionar recursos alocados ao fator de excesso ou a outras execuções estratégicas.

Quanto ao fator (1), consideraram que a estrutura interna montada para ele pode ser diminuída ou até desativada, haja vista a velocidade com que novos produtos são lançados e o preço baixando. Talvez seja mais viável repor itens que retornam com unidades novas ou com novos modelos. Outra alternativa possível é terceirizar o serviço com empresas locais de assistência técnica. Com qualquer solução, é possível a liberação de recursos materiais, humanos e financeiros com a diminuição desta atividade.

O fator (7) é uso de testes acelerados para detecção de problemas de projeto. A necessidade de ação já foi detectada devido à entrada no mercado de uma empresa que usa e anuncia seus resultados como arma de competição. A empresa contratou um projeto de pesquisa junto a uma universidade, já fez testes acelerados com laboratórios credenciados e já se apropriou de, ao menos, um modo de fazer estes testes. O fator (11), conhecimento da confiabilidade do produto como arma de competição, está relacionado com (7). O mercado já começou a exigir cálculos de confiabilidade como requisito de decisão de negócios e alguns concorrentes já estão oferecendo este cálculo em suas propostas. Um departamento de engenharia de confiabilidade talvez pudesse ser organizado para sistematizar este assunto. Parte dos recursos para este departamento poderia vir da atual assistência técnica. Os fatores (12) e (13) podem ser analisados juntos, pois tratam do uso da noção de confiabilidade para o atual cálculo da garantia e para modelos avançados de cálculo. Atualmente, a empresa define o prazo de garantia exclusivamente por aspectos de mercado: não pode ficar abaixo dos concorrentes e deve se adequar à legislação. Os gestores manifestaram desconhecer métodos de cálculo de garantia baseados na confiabilidade, mas após tomar conhecimento, perceberam-nos como armas de competição viáveis no mercado em que atuam. Caso a empresa conheça a confiabilidade sistêmica do produto, pode usar esta informação para realimentar o projeto e elevar o prazo de garantia com segurança. Este quesito costuma ser importante e algumas vezes já foi decisivo em licitações que a empresa toma parte. O fator (15) trata de sistema de informação para apoio à prospecção de mercado, vendas e negociação. Os gestores apontam a falta de

Quadro 2. Síntese de linhas de ação segundo os gestores centralizados.

\begin{tabular}{|c|c|c|}
\hline Fator de competição & Situação & Principais ações sugeridas \\
\hline $\begin{array}{l}\text { (1) Reparos em bancada } \\
\text { ou oficina }\end{array}$ & $\begin{array}{l}\text { Excesso } \\
(-1,67)\end{array}$ & $\begin{array}{l}\text { Reduzir alocação de recursos } \\
\text { materiais e humanos na sede e distribuidores }\end{array}$ \\
\hline $\begin{array}{l}\text { (7) Testes } \\
\text { acelerados }\end{array}$ & $\begin{array}{c}\text { Falta } \\
(1,67)\end{array}$ & $\begin{array}{l}\text { Sistematizar rotina e compor bancada de } \\
\text { testes acelerados para novos projetos }\end{array}$ \\
\hline $\begin{array}{l}\text { (11) Confiabilidade } \\
\text { em projeto }\end{array}$ & $\begin{array}{c}\text { Falta } \\
(1,83)\end{array}$ & $\begin{array}{l}\text { Compor departamento de engenharia de confiabilidade para } \\
\text { apoiar ações de projeto que aumentem a confiabilidade }\end{array}$ \\
\hline $\begin{array}{l}\text { (12) Confiabilidade } \\
\text { em garantia }\end{array}$ & $\begin{array}{l}\text { Falta } \\
(1,50)\end{array}$ & $\begin{array}{l}\text { Uma missão do departamento de confiabilidade seria calcular o impacto } \\
\text { da garantia no custo do produto (Calcular o impacto da garantia no custo } \\
\text { do produto - responsável: departamento de engenharia de confiabilidade) }\end{array}$ \\
\hline $\begin{array}{l}\text { (13) Confiabilidade em } \\
\text { novas garantias }\end{array}$ & $\begin{array}{c}\text { Falta } \\
(1,83)\end{array}$ & $\begin{array}{l}\text { Outra missão seria calcular novas garantias sob o impacto da confiabilidade } \\
\text { aumentada (Calcular novas garantias sob o impacto da confiabilidade } \\
\text { aumentada - responsável: departamento de engenharia de confiabilidade) }\end{array}$ \\
\hline $\begin{array}{l}\text { (15) Sistema de informação } \\
\text { para prospecção }\end{array}$ & $\begin{array}{l}\text { Falta } \\
(2,00)\end{array}$ & $\begin{array}{l}\text { Construir um sistema de informação baseado em informações } \\
\text { de uso e desempenho de produtos }\end{array}$ \\
\hline $\begin{array}{l}\text { (16) Sistemas de } \\
\text { informação para clientes }\end{array}$ & $\begin{array}{c}\text { Falta } \\
(1,50)\end{array}$ & $\begin{array}{l}\text { Criar uma newsletter para divulgar inovações de projeto e } \\
\text { modificações em produtos existentes }\end{array}$ \\
\hline
\end{tabular}


adequação do sistema existente e a necessidade de melhorias estruturais nele, para que possa cumprir a tarefa. Por fim, o fator (16), apoio documental ao relacionamento com clientes, foi apontado como carente. Os gestores sugeriram newsletter para colocar os clientes a par das inovações e para resposta de dúvidas. Muitas vezes, a mesma dúvida ou informação é demandada por expressivo número de clientes. As insatisfações quanto às dúvidas e aos custos dos atendimentos repetidos poderiam ser prevenidos por tais mecanismos de comunicação empresarial.

A situação dos fatores priorizados foi sintetizada no Quadro 2. A coluna do meio traz o tamanho da lacuna do fator, o que pode ser associado à sua prioridade.

A análise do caso-piloto foi baseada exclusivamente na opinião e na visão dos gestores de pós-venda que operam a partir da sede na empresa. Não considera a visão dos distribuidores.

Uma análise que poderia ter sido útil seria a análise fatorial, baseada no método dos componentes principais ou em outro método. O resultado indicaria se existe uma estrutura de fatores subjacente aos fatores investigados que poderia simplificar a análise estratégica. No entanto, os testes KMO e de Bartlett de esfericidade não ofereceram resultado satisfatório quanto à correlação presente nas respostas, indicando que a amostra não é adequada para a análise fatorial. Observa-se que três variáveis apresentaram variância nula (fatores 5,7 e 16).

\section{Considerações finais}

O objetivo deste artigo foi construir uma estrutura de temas da estratégia de pós-venda de uma empresa de manufatura de base tecnológica. Foram revisados conceitos sobre operações de pós-venda. Por técnica de grupos focados com quatro especialistas praticantes e três acadêmicos, mediado por pesquisador, foi construída uma estrutura em forma de árvore que organiza os temas e os fatores de competição em pós-venda. A estrutura foi testada numericamente por meio de um questionário aplicado a três gestores da operação de pós-venda de uma empresa fabricante de equipamentos necessários na estrutura. Os resultados da aplicação do questionário serviram para uma análise estratégica da operação. O estudo é exploratório e limitado aos gestores da sede central da operação.

O uso do método pode ter implicações em gestão estratégica de pós-venda. Além de priorizar ações e apoiar tomadas de decisão, o método pode ser útil para comparações entre operações similares e, principalmente, servir como elo de realimentação para a execução da estratégia de pós-venda. À medida que a estratégia vai sendo executada, o modelo vai informando o quanto avançam os resultados e que trocas entre alocações de recursos podem ser mais favoráveis. É possível formar séries históricas de importâncias e desempenhos que reflitam a trajetória irreversível de um fenômeno complexo, tal como a operação de pós-venda de uma manufatura de base tecnológica.

Na continuidade, a pesquisa será estendida à rede de distribuidores da empresa.

\section{Agradecimentos}

Os autores reconhecem a importância dos gestores e especialistas que participaram da pesquisa. A pesquisa foi integralmente financiada pelo $\mathrm{CNPq}$.

\section{Referências}

AMINI, M.; RETSZAFF-ROBERTS, D.; BIENSTOCK, C. Designing a reverse logistics operation for short cycle time repair services. International Journal of Production Economics, v. 96, n. 3, p. 369-380, 2005.

BACCHETTI, A. et al. The outsourcing of product service provision for durable consumer goods. a methodology for process and performance assessment of third party service shops. In: EUROMA, 15., 2008, Groningen, Holanda. Proceeding...

BALLOU, R. Gerenciamento da cadeia de suprimentos: planejamento, organização e logística empresarial. Porto Alegre: Bookman, 2001.

BARRY, J.; TERRY, T. Empirical study of relationship value in industrial services. Journal of Business $\boldsymbol{\&}$ Industrial Marketing, v. 23, n. 4, p. 228-241, 2008.

BORCHARDT, M.; SELLITTO, M.; PEREIRA, G. Serviços de pós-venda para produtos fabricados em base tecnológica. Produção Online, v. 8, n. 1, p. 1-25, 2008.

BRAX, S. A manufacturer becoming service provider challenges and a paradox. Managing Service Quality, v. 15, n. 2, p. 142-155, 2005.

BUNDSCHUH, R.; DEZVANE, T. How to make after sale services pay off. The Mckinsey Quarterly, v. 4 , n. 1, p. 116-127, 2003.

CARVALHO, M; LAURINDO, F. Estratégia competitiva dos conceitos à implementação. São Paulo: Atlas, 2007.

CAVALIERI, S.; GAIARDELI, P.; IERACE, S. Aligning strategic profiles with operational metrics in after-sales service. International Journal of Productivity and Performance Management, v. 56, n. 5/6, p. 436-455, 2007.

COHEN, M.; AGRAWAL, N.; AGRAWAL, V. Winning in the aftermarket. Harvard Business Review, v. 84, n. 5, p. 129-138, 2006.

CORREAA, H.; CAON, M. Gestão de serviços: lucratividade por meio de operações e satisfação dos clientes. São Paulo: Atlas, 2002.

DENNIS, M.; KAMBIL, A. Service management: Building profits after the sales. Supply Chain Management Review, v. 7, n. 1, p. 42-48, 2003.

EISENHARDT, K. Building theories from case study research. Academy of Management Review, v. 14, n. 4, p. 532-550, 1989

FIGUEIREDO, K. A logística do pós-venda. 2002. Disponível em: <http://www.cel.coppead.ufrj.br/fs-busca. htm?fr-log-pvenda.htm>. Acesso em: 18 ago. 2005.

FRENCH, S. Decision theory: an introduction to the mathematics of rationality. Chichester, West Sussex, UK: Ellis Horwood, 1986.

GAIARDELLI, P.; SACCANI, N.; SONGINI, L. Performance measurement systems in after-sales service: an integrated framework. International Journal of 
Business Performance Management, v. 9, n. 2, p. 145-171, 2007.

GEBAUER, H. Identifying service strategies in product manufacturing companies by exploring environmentstrategy configurations. Industrial Marketing Management, v. 37, n. 3, p. 278-291, 2008.

HAIR, J. et al. Multivariate data analysis. New Jersey: P. Hall, 1998.

HAYES, B. Medindo a satisfação do cliente: desenvolvimento e uso de questionários. Rio de Janeiro: Qualitymark, 2001.

HAYS, J.; HILL, A. A longitudinal study of the effect of a service guarantee on service quality. Production and Operations Management, v. 10, n. 4, p. 405-424, 2001.

HESKETT, J.; SASSER, W.; SCHESINGER, L. Lucro na prestação de serviços: como crescer com a lealdade e satisfação dos clientes. Rio de Janeiro: Ed. Campus, 2002.

HIRSCH, B.; ESCHENBÄCHER, J. Extended Products in dinamyc enterprises: the IST project cluster EXPIRE. In: STANFORD-SMITH, B.; KIDD, P. (Org.). E-business: key issues, applications and technologies. Amsterdam: IOS Press, 2000. p. 622-628.

HULL, D., COX, J. The field service function in the electronics industry: Providing a link between customers and production/marketing. International Journal of Production Economics, v. 37, n. 1, p. 115-126, 1994.

JOHNSTON, R.; CLARK, G. Administração de operações de serviço. São Paulo : Ed. Atlas, 2002.

LELE, M. After-sales service - necessary evil or strategic opportunity? Managing Service Quality, v. 7, n. 3, p. 141-145, 1997.

LOVELOCK, C.; WRIGHT, L. Serviços: marketing e gestão. São Paulo: Saraiva, 2002.

LUZ, S.; SELLITTO, M.; GOMES, L. Medição de desempenho ambiental baseada em método multicriterial de apoio à decisão: estudo de caso na indústria automotiva. Gestão \& Produção, v. 13, n. 3, p. 557-570, 2006.

MALTHOUSE, E. et al. Customer Satisfaction Across Organizational Units. Journal of Service Research, v. 6, n. 3, p. 231-242, 2004.

MATHIEU, V. Service strategies within the manufacturing sector: benefits, costs and partnership. International Journal of Service Industry Management, v. 12, n. 5, p. 451-475, 2001

OLIVA, R.; KALLENBERG, R. Managing the transition from products to services. International Journal of Service Industry Management, v. 14, n. 2, p. 160-172, 2003.

PAIVA, E.; CARVALHO, L; FENSTENSEIFER, J. Estratégia de produção e de operações. Porto Alegre: Bookman, 2004.

RIBEIRO, J.; NEUMANN, C. Planejamento e condução de grupos focados. In: RIBEIRO, J. (org.) Grupos focados: teoria e aplicações. Porto Alegre: FEENGUFRGS-PPGEP, 2003.

ROESCH, S. Projetos de estágio e de pesquisa em administração: guia para estágios, trabalhos de conclusão, dissertações e estudos de caso. São Paulo: Atlas, 1999.

ROTH, A.; MENOR, L. Insights into service operations management: a research agenda. Production and Operation Management, v. 12, n. 2, p. 145-165, 2003.
SACCANI, N.; JOHANSSON, P.; PERONA, M. Configuring the after-sales service supply chain: A multiple case study. International Journal of Production Economics, v. 110, n. 1, p. 52-69, 2007.

SELLITTO, M. Medição e controle de desempenho estratégico em sistemas de manufatura. Tese(Doutorado em Engenharia de Produção). Escola de Engenharia, UFRGS, Porto Alegre, 2005.

SELLITTO, M.; RIBEIRO, J. Construção de indicadores para avaliação de conceitos intangíveis em sistemas produtivos. Gestão \& Produção, v. 11, n. 1, p. 75-90, 2004.

SELLITTO, M.; WALTER, C. Avaliação do desempenho de uma manufatura de equipamentos eletrônicos segundo critérios de competição. Produção, v. 16, n. 1, p. 34-47, 2006.

SLACK, N. Vantagem competitiva em manufatura: atingindo competitividade nas operações industriais. São Paulo: Atlas, 1993.

STEWART, D. Piecing together service quality: a framework for robust service. Production and Operations Management, v. 12, n. 2, p. 246-266, 2003.

SUOMALA, P.; SIEVANEN, M.; PARANKO, J. Customization from the after sales point of viewimplications of product and item customization for spare-part business. Technovation, v. 24, n. 10, p. 831-840, 2004.

SUOMALA, P.; SIEVANEN, M.; PARANKO, J. Customization on capital goods: implications for after-sales. In: RAUTENSTRAUCH, C.; SEELMANNEGGEBERT, R.; TUROWSKI, C. (Org.) Moving into mass customization: information systems and Management Principles. Berlin: Springer-Verlag, 2002. p. 231-248.

VAN DAAL, J. Knowledge management in after-sales organizations: exploring determinants of knowledge processes. Master Thesis-Erasmus University Rotterdan, 2004

VIARDORT, E. Successful marketing for high-tech firms. Norwood: Ed. Artech House, 2004.

VOSS, C.; TSIKRIKTSIS, N.; FROLICH, M. Case research in operations management. International Journal of Operations and Production Management, v. 22, n. 2, p. 195-219, 2002.

WAGNER, S.; ZELLWEGER, T.; LINDEMANN, E. Erfolgreiches After Sales Service Management: Durch einen strategie- und lebenszyklusorientierten Ansatz lassen sich Potenziale ausschöpfen. Industrie Management, v. 23, n. 1, p. 60-63, 2007.

WISE, R.; BAUMGARTNER, P. Go downstream-The new profit imperative in manufacturing. Harvard Business Review, v. 77, n. 5, p. 133-141, 1999.

YANAMANDRAM, V.; WHITE, L. Switching barriers in business-to-business services: a qualitative study. International Journal of Service Industry Management, v. 17, n. 2, p. 158-192, 2006.

YIN, R. Estudo de caso: planejamento e método. Porto Alegre: Bookman, 2001.

ZACKARIASSON, P.; WILSON, T. Internetworked aftersales service. Industrial Marketing Management, v. 33 , n. 2 , p. 75-86, 2004. 